\title{
Sputum microbiota in normal human, new tb patients, and recurrent tuberculosis patients as identified by 16SrRNA sequencing
}

\author{
Muh. Nasrum Massi ${ }^{1, *}$, Sitti Rafiah ${ }^{2}$, Mudyawati Kamaruddin $^{3}$, Najdah Hidayah ${ }^{4}$, Handayani $^{5}$, Rufika Shari \\ Abidin $^{1}$
}

\author{
${ }^{1}$ Microbiology Department, Medical Faculty, Hasanuddin University, Indonesia. \\ ${ }^{2}$ Anatomy Department, Medical Faculty, Hasanuddin University, Indonesia. \\ ${ }^{3}$ Midwifery Academy of Tahirah Al Baeti Bulukumba, Indonesia. \\ ${ }^{4}$ Postgraduate Program, Medical Faculty, Hasanuddin University, Indonesia. \\ ${ }^{5}$ Hasanuddin University Medical Research Center, Medical Faculty, Hasanuddin University, Indonesia.
}

*Corresponding author: Email: vicerector4@unhas.ac.id, nasrumm2000@yahoo.com; Mailing address: HUM-RC Laboratory RS Universitas Hasanuddin, Gedung A, Lantai 6, Jl. Perintis Kemerdekaan Km. 11 Tamalanrea, Makassar 90245 Sulawesi Selatan, Indonesia.

\begin{abstract}
Background: Recent developments lead to a new understanding that diseases are interconnected with each other and may be affected by microbiome community imbalance, known as dysbiosis. Our research is aimed to examine lung microbiome in recurrent and new TB patients compared to healthy individuals.

Methods: Our research uses the cross-sectional method with a metagenomic approach for genomic analysis by directly isolating genome DNA from sputum of new TB, recurrent TB patients and healthy individuals. DNA sequencing results were analysed with the MEGA 7.026 software with the BLASTn algorithm in NCBI-

Results: 16 sputum samples have been successfully sequenced. We found Haemophilus in the sputum of new and recurrent TB patients ( $50 \%$ and $22.2 \%$ respectively), which absent in the sputum of healthy controls. Specifically, we identified only Haemophilus influenza and Neisseria flavescens in new TB patients but we found Haemophilus influenza and Streptococcus pneumonia in the sputum of recurrent TB patients.
\end{abstract}

Conclusion: Haemophilus was found in new and recurrent TB patients. Haemophilus influenza and Streptococcus pneumonia may contributed in TB recurrence.

Keyword: microbiota, tuberculosis, 16s rRNA sequencing 


\section{Introduction}

Mycobacterium tuberculosis (Mtb) is a bacteria cause tuberculosis (TB) that is still a main problem of infectious disease. By 2017, there were approximately 10.4 million new TB incidence cases worldwide. Indonesia ranks third among TB high burden countries, with estimated more than 800.000 cases [1]. The issue of TB increases with the presence of Multidrug-resistant (MDR) cases, TB patients with irregular therapy will be a dangerous source of transmission, because the transmitted TB germs may be resistant to two or more anti-tuberculosis drugs $[2,3]$. Multidrug resistance is the biggest problem against TB prevention and eradication. This adds to the burden of TB control and shows the incomplete TB disease control in the community as evidenced by the presence of relapse or recurrent TB patients.

Tuberculosis drug regulation in tuberculosis patients should consider the adverse effects of tuberculosis drugs as well as the genetic aspects of drug-induced tuberculosis in patients. Administration of drugs continuously and repeatedly may have adverse drug reaction effects on the body's metabolism and biomolecules. One effect is the disruption of the microbiome community diversity which inhabits the domains of the human body. Although microbiomes have a good effect on the body, the presence of external factors such as diet, irrational antibiotics, and infections can affect the composition of microbiomes called dysbiosis [4]. A number of studies have shown evidence of dysbiosis associated with the development and progression of the disease. It may increase the risk of infection [4] and also determines the outcome of the infectious disease in the human host [5]. A study conducted by Hong et al. reveals that microbiome changes are associated with antibiotic therapy in TB patients [6]. Further understanding of microbial variations in human microbiomes provides new knowledge about new therapies, such as the culture of good bacteria in patients to treat infections due to bad bacteria.

The development of high-throughput sequencing technology has been applied to identify the composition of microbiota that residues in different part of body [7], including in the lung, which is detected by 16S rRNA sequencing $[8,9]$. The presence of disruption of the microbiota in lower respiratory tract may be associated with pulmonary diseases such as chronic obstructive pulmonary disease (COPD) $[9,10]$, asthma [11] and cystic fibrosis [12]. This study investigates the microbiome diversity in tuberculosis, comparing healthy and tuberculosis patients. Studies in this field have been reported but are still limited [13-16]. In this study, we investigate the metagenomic diversity of the microbiome in sputum samples from TB patients, the new cases of pulmonary TB and recurrent TB, by employing 16s rRNA sequencing. Understanding the diversity of lung microbial composition in different states of tuberculosis may describe the association between microbiome and immunity, especially in recurrent TB patients, and the systemic function of the microbiome, and may give an alternative solution on recurrent TB.

\section{Material and Methods}

\section{Ethics Statement}

This study was approved by the Research Ethical Committee of Medical Faculty, Hasanuddin University, Makassar, Indonesia. Written informed consent was obtained from all the participants in this study. Information about the participant includes age, clinical manifestation, history of the disease, laboratory results and chest x-ray were collected.

\section{Sample collection and DNA Extraction}

This study analyzed the microbiota in sputum samples from new and recurrent TB patients compared to healthy individuals. A total of 13 samples of TB patients consist of 4 new pulmonary TB patients and 9 recurrent TB patients. We also recruited 3 healthy controls, which were free of disease and have no cough symptoms. Each sputum sample was extracted by DNA using a gSYNCTM DNA Extraction Kit (Geneaid) following their respective protocol kits.

\section{PCR Amplification and Sequencing}

The PCR enrichment of the 16S rRNA was performed using primer U1 (5'- CCAGCAGCCGCGGTATACG-3') corresponding to nucleotides 518 to 537 of the E.coli $16 \mathrm{~S}$ rRNA gene and U2 (5'ATCGG(C/T)TACCTTGTTACGACTTC-3') corresponding to nucleotides 1513 to 1491 of the same gene [Lu, 2000]. PCR conditions were predenaturation $94{ }^{\circ} \mathrm{C}$ for $5 \mathrm{~min}$, followed by denaturation at $94{ }^{\circ} \mathrm{C}$ for $30 \mathrm{~s}$, annealing 
at $63{ }^{\circ} \mathrm{C}$ for $30 \mathrm{~s}$ and extension at $72{ }^{\circ} \mathrm{C}$ for $40 \mathrm{~s}$ in 30 cycles using GoTaq ${ }^{\circledR}$ Master Mix (Promega, Madison, USA). The target size of PCR product was $996 \mathrm{bp}$. The extracted DNA was prepared for sequencing with the ABI Prism BigDye ${ }^{\circledR}$ Terminator v3.1 Cycle Sequencing kit (Applied Biosystems, USA) and then run on Applied Biosystems 3730xl Genetic Analyzer (Life Technologies).

\section{Data Analysis}

We analyzed the sequences result using MEGA 7.026 and BLAST software in the gene bank of NCBI. The chromatogram of the sequenced results was edited using MEGA 7.026 software and searched for similarities with the BLASTn algorithm method of NCBI.

\section{Results}

\section{Participant characteristic}

The characteristics of the participants in this study are described in Table 1. In this study, the percentage of males are higher than females in the TB patient group: $77.7 \%$ in recurrent TB cases group; and $75 \%$ in new TB cases group. The average age of patients in the new TB cases group was $52 \pm 24.45$ years, while the average age of patients in the recurrent TB cases group was 25 years within 17-76 years age range. The dominant nutritional status of recurrent TB patient is underweight (77.8\%), while patients in the new TB cases group could be categorised to have a normal nutritional status (75\%) and underweight nutritional status $(25 \%)$. The average age of healthy participants was 18 years. All of the healthy participants were female.

Table 1. Participant Characteristics

\begin{tabular}{|c|c|c|c|c|}
\hline $\begin{array}{l}\text { Participant } \\
\text { Characteristics }\end{array}$ & $\begin{array}{c}\text { New TB cases } \\
\quad N=4\end{array}$ & $\begin{array}{c}\begin{array}{c}\text { Recurrent } \mathrm{TB} \\
\text { cases } \\
\mathrm{N}=9\end{array} \\
\end{array}$ & $\begin{array}{c}\text { Healthy } \\
\text { participants } \\
\mathrm{N}=\mathbf{3}\end{array}$ & $\mathbf{p}$ \\
\hline Age (mean \pm SD) & $52 \pm 24.45$ & $51 \pm 9.01$ & $18 \pm 1$ & 0.07 \\
\hline \multicolumn{5}{|l|}{ Sex } \\
\hline - Male & $3(75 \%)$ & $7(77.7 \%)$ & - & 0.046 \\
\hline - Female & $1(25 \%)$ & $2(22.2 \%)$ & $3(100 \%)$ & \\
\hline \multicolumn{5}{|l|}{ Main complaints } \\
\hline - Haemoptysis & $(100 \%)$ & $3(33.33 \%)$ & - & 0.084 \\
\hline - Dyspnea & - & $5(55.56 \%)$ & - & (between new \\
\hline - Cough & - & $1(11.11)$ & - & and TB cases) \\
\hline Smoking habit & $\begin{array}{ll}1 & (25 \%)\end{array}$ & $4(44.44 \%)$ & - & 0.339 \\
\hline Alcohol use & $1 \quad(25 \%)$ & $2(22.22 \%)$ & - & 0.649 \\
\hline $\begin{array}{l}\text { TB history/chronic cough } \\
\text { in the family/ people } \\
\text { around the patient (such } \\
\text { neighbours or close } \\
\text { friends) }\end{array}$ & $2 \quad(50 \%)$ & - & - & 0.032 \\
\hline $\begin{array}{l}\text { BMI in } \mathrm{kg} / \mathrm{m}^{2} \text { (mean } \pm \\
\text { SD) }\end{array}$ & $19.92 \pm 2.3$ & $16.2 \pm 2.46$ & $19.92 \pm 1.12$ & 0.032 \\
\hline
\end{tabular}

Sputum microbiome comparison of relapse TB, new TB, and healthy participant cases.

Based on the analysis of DNA sequence obtained in this study, among 9 sputum samples of recurrent TB patients, Streptococcus were found in 7 samples (77.8\%) and Haemophilus were found in 2 samples (22.2\%). Meanwhile, of 4 samples of new TB patients, Streptococcus were found in one (25\%) of them, Neisseria in one (25\%) sample, and Haemophilus in two (50\%) samples. Among 3 sputum samples of healthy controls, there were Streptococcus in two $(66.7 \%)$ samples, and Bulkholderia $(33.3 \%)$ in one sample. 
At the phyla level, Proteobacteria were found in 2 sputum samples (22.2\%) and Firmicutes were found in 7 sputum samples (77.8\%) of recurrent TB patients. Among 4 samples of new TB cases, Proteobacteria and Firmicutes were found in equal percentage (50\%). While in healthy controls, Firmicutes were found in 2 samples $(66.7 \%)$ and Proteobacteria were found in 1 sample (33.3\%).

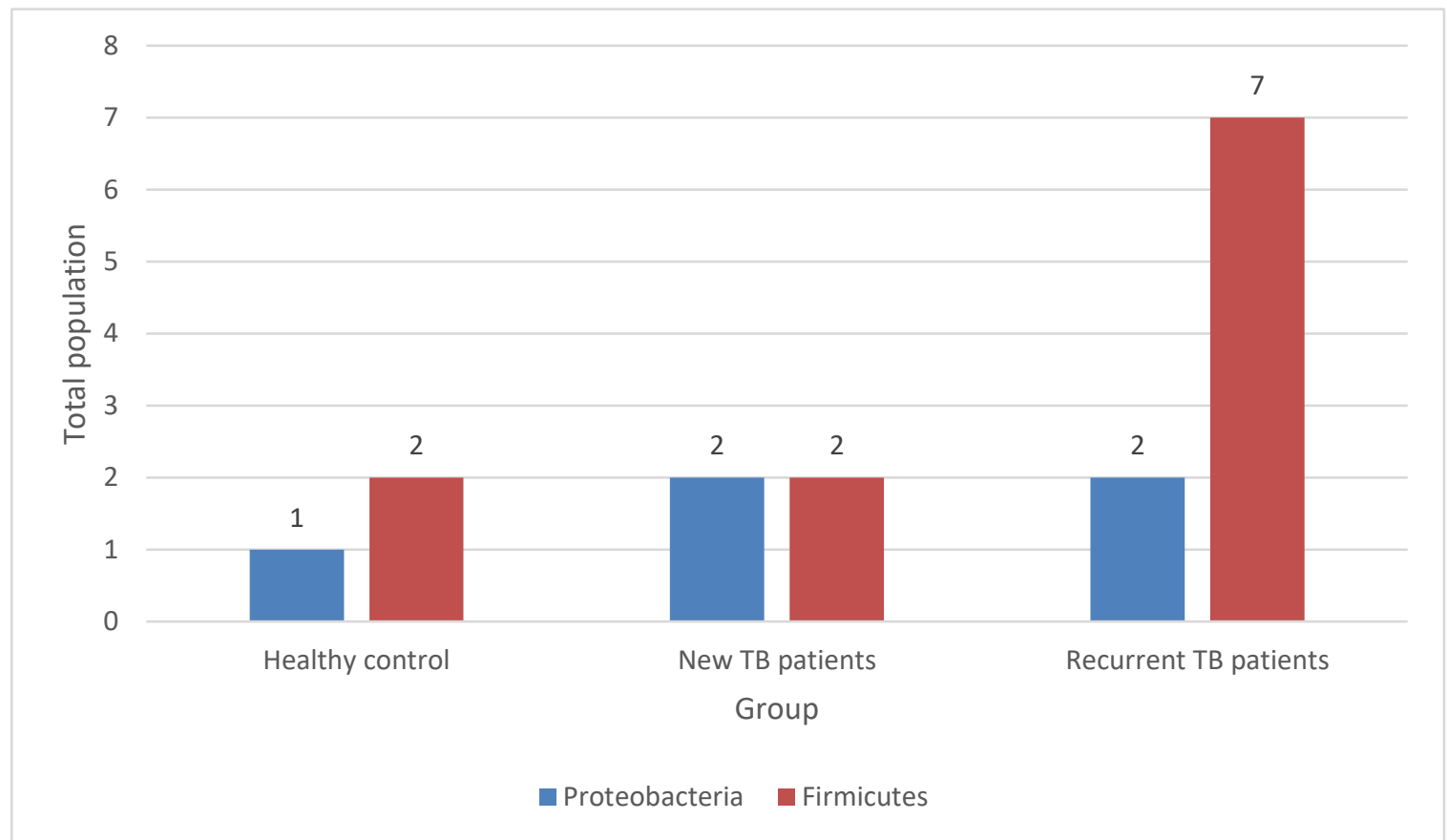

Species Haemophilus influenza were identified in TB patients (50\% in new cases and $22.2 \%$ in recurrent cases) and absent in healthy controls. We also found that there were Streptococcus pneumonia in $22.2 \%$ sputum samples of recurrent TB patients, which absent in other group.

Figure 1. Sputum microbiota profile in new TB, relapse TB, and healthy cases at phyla level. 


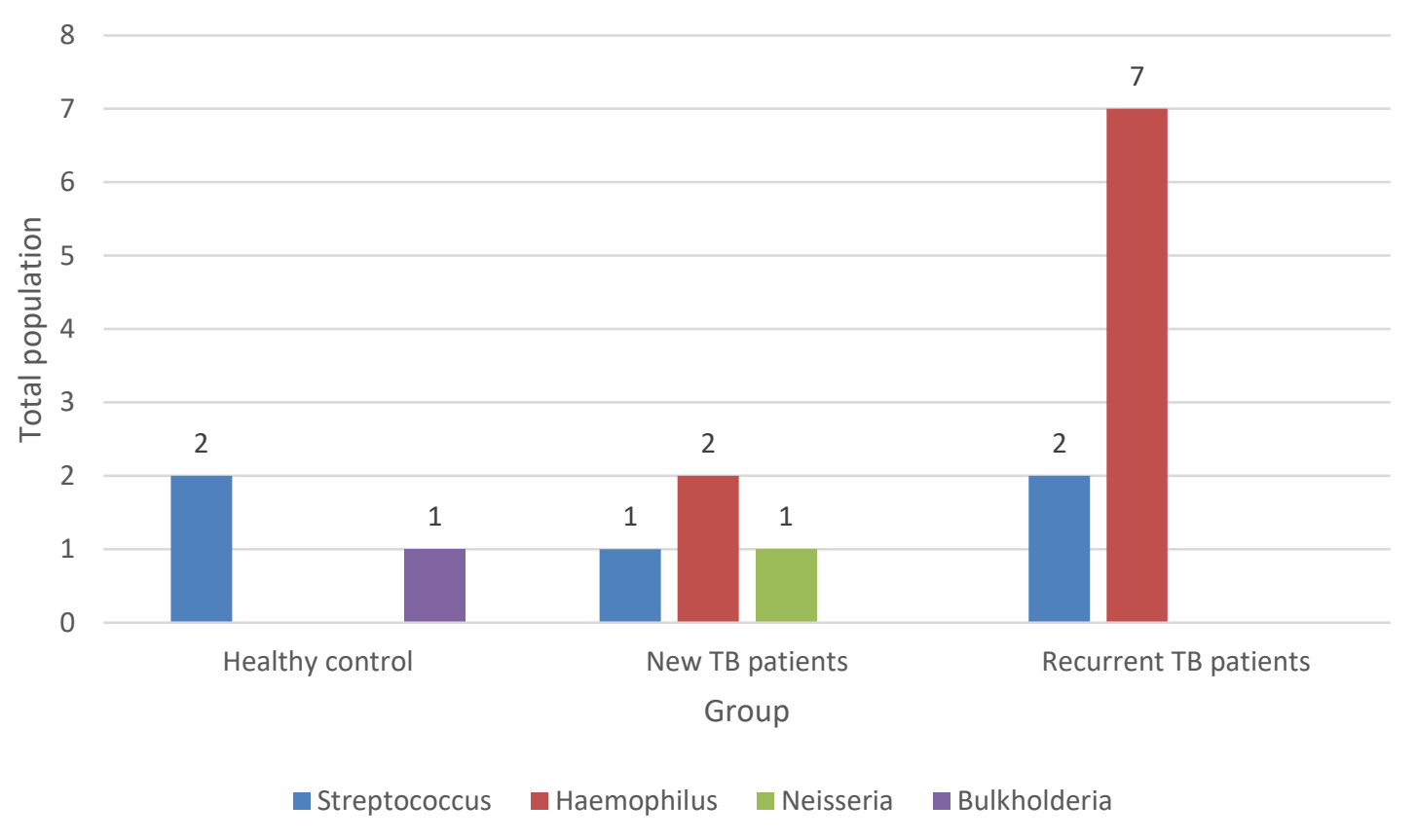

Figure 2. Sputum microbiota profile in new TB, relapse TB, and healthy cases at genera level.

\section{Discussion}

A number of studies about microbiome composition in the sputum of TB patients have been reported. Cheung et al (2013) recruited patients with non-TB cough symptoms as controls and showed similar microbiota diversity among TB patients and control[13]. On the other hand, Cui et al (2012) and Wu et al (2013) showed that there was a difference in microbiota diversity between the sputum of TB patients and healthy participants, their research discovered different microbiota profiles for the respective groups. The study of Cui et al. showed that the sputum of TB patients had a higher diversity than healthy patients, while the study of Wu et al. (2013) showed the contrary[14, 15]. Studies conducted by Cheung et al. (2013) in China, demonstrated that members of the phyla Proteobacteria and Bacteroidetes were percentage-base more dominant in TB patients, while the phylum Firmicutes was more dominant in control samples (patient with non-TB cough symptoms)[13]. In contrast, studies conducted in India by Krishna et al (2016) revealed differences between the Chinese and Indian populations. Proteobacteria and Bacteroidetes had a more significant representation in the samples of healthy participants, while Firmicutes and Actinobacteria were more dominant in TB patients in the Indian population [16]. Our own results in Makassar population showed that Firmicutes and Proteobacteria were found in the sputum microbiota of TB patients, both new and relapse cases, and also in healthy individuals with no significant difference.

At genera level, we found Haemophilus in the sputum of new and recurrent TB patients $(50 \%$ and $22.2 \%$ respectively), which absent in the sputum of healthy controls. In new TB patients, Streptococcus were found in one $(25 \%)$ of them, Neisseria in one $(25 \%)$ sample, and Haemophilus in two $(50 \%)$ samples. Meanwhile in recurrent TB patients, Streptococcus were found in 7 samples (77.8\%) and Haemophilus were found in 2 samples $(22.2 \%)$. There was a similarity with Indian population and Chinese population. Krishna revealed that Streptococcus was dominant genera in TB patients in Indian population. However, Streptococcus was also dominant genera in normal individual in the same study [16]. Meanwhile, Wu reported that Streptococcus were more abundant in TB patients in Chinese population [15].

\section{Conclusion}

Based on the results obtained from this study, Haemophilus was found in new and recurrent TB patients. Haemophilus influenza and Streptococcus pneumonia may contributed in TB recurrence. At the phyla level, there was no significant difference between lung microbiota of TB patients and healthy individual. In the future, we hope to be able to conduct a research with larger amounts of samples, on different locations, and with a more 
developed method and design.

\section{Conflict of interest statement}

We declare that we have no conflict of interest.

\section{Acknowledgement}

Funding for this study was provided by grant from the Lembaga Penelitian dan Pengabdian Masyarakat Hasanuddin University No. 15157/UN4.3.2/LK.23/2017.

\section{References}

[1] World Health Organization. Global Tuberculosis Report 2018. Geneva: World Health Organization, 2018.

[2] Maertzdorf J, Repsilber D, Parida SK, et al. Human gene expression profiles of susceptibility and resistance in tuberculosis. Genes Immun 2011; 12: 15-22.

[3] Munir S., Arifin N, Dianiati KS. Pengamatan Pasien Tuberkulosis Paru dengan Multidrug Resistant (TBMDR) di Poliklinik Paru RSUP Persahabatan. J Respir Indo 2010; 30: 92-103.

[4] Dietert R, Dietert J. The Microbiome and Sustainable Healthcare. Healthcare 2015; 3: 100-129.

[5] Wang F, Roy S. Gut Homeostasis, Microbial Dysbiosis, and Opioids. Toxicol Pathol 2017; 45: 150-156.

[6] Hong B, Adami AJ, Granados H, et al. Microbiome Changes during Tuberculosis and Antituberculous Therapy. Clin Microbiol Rev 2016; 29: 915-926.

[7] Huttenhower C, Gevers D, Knight R, et al. Structure, function and diversity of the healthy human microbiome. Nature 2012; 486: 207-214.

[8] Erb-Downward JR, Thompson DL, Han MK, et al. Analysis of the lung microbiome in the 'healthy' smoker and in COPD. PLoS One; 6. Epub ahead of print 2011. DOI: 10.1371/journal.pone.0016384.

[9] Sze MA, Dimitriu PA, Hayashi S, et al. The lung tissue microbiome in chronic obstructive pulmonary disease. Am J Respir Crit Care Med 2012; 185: 1073-1080.

[10] Huang YJ, Kim E, Cox MJ, et al. A Persistent and Diverse Airway Microbiota Present during Chronic Obstructive Pulmonary Disease Exacerbations. Omi A J Integr Biol 2010; 14: 9-59.

[11] Hilty M, Burke C, Pedro H, et al. Disordered microbial communities in asthmatic airways. PLoS One; 5. Epub ahead of print 2010. DOI: 10.1371/journal.pone.0008578.

[12] Zhao J, Schloss PD, Kalikin LM, et al. Decade-long bacterial community dynamics in cystic fibrosis airways. Proc Natl Acad Sci 2012; 109: 5809-5814.

[13] Cheung MK, Lam WY, Fung WYW, et al. Sputum Microbiota in Tuberculosis as Revealed by 16S rRNA Pyrosequencing. PLoS One; 8. Epub ahead of print 2013. DOI: 10.1371/journal.pone.0054574.

[14] Cui Z, Zhou Y, Li H, et al. Complex sputum microbial composition in patients with pulmonary tuberculosis. BMC Microbiol; 12. Epub ahead of print 2012. DOI: 10.1186/1471-2180-12-276.

[15] Wu J, Liu W, He L, et al. Sputum microbiota associated with new, recurrent and treatment failure tuberculosis. PLoS One 2013; 8: 1-11.

[16] Krishna P, Jain A, Bisen PS. Microbiome diversity in the sputum of patients with pulmonary tuberculosis. Eur J Clin Microbiol Infect Dis 2016; 35: 1205-1210. 